\title{
Probe-corrected spherical near-field antenna measurements
}

\section{Larsen, Flemming Holm}

\section{Published in:}

I E E E Transactions on Antennas and Propagation

Publication date:

1984

Document Version

Publisher's PDF, also known as Version of record

Link back to DTU Orbit

Citation (APA):

Larsen, F. H. (1984). Probe-corrected spherical near-field antenna measurements. I E E E Transactions on Antennas and Propagation, 32(9), 1012.

\section{General rights}

Copyright and moral rights for the publications made accessible in the public portal are retained by the authors and/or other copyright owners and it is a condition of accessing publications that users recognise and abide by the legal requirements associated with these rights.

- Users may download and print one copy of any publication from the public portal for the purpose of private study or research.

- You may not further distribute the material or use it for any profit-making activity or commercial gain

- You may freely distribute the URL identifying the publication in the public portal

If you believe that this document breaches copyright please contact us providing details, and we will remove access to the work immediately and investigate your claim 
$\pi$ and $\beta_{c}=\beta_{0 c}$. Since the four angles, $\phi, \phi^{\prime}, \beta_{c}$, and $\beta_{0 c}$ are mutually independent, the argument of $F$ in (1) may take any value between 0 and $\infty$ and, accordingly, $F$ may take any value between 0 and 1 , depending on the way the diffracted ray approaches the direction of reflection (incidence). As a result, the calculated corner diffracted field is nonunique for these directions and its behavior in the adjacent transition regions is far from being the true physical behavior. In particular, this should lead to incorrect re. sults for the backscatter from flat plates in the directions close to normal. Indeed, according to $(7)^{1}$, the comer diffraction coefficient for nearly normal backscattering is dominated by the term

$$
D_{s, h}^{c} \sim \pm \frac{j \tan \beta_{c}}{8 \pi \cos \phi}\left|F\left(\frac{\cos ^{2} \phi / \lambda}{k \cos ^{2} \beta_{c}}\right)\right|,
$$

which diverges as $\phi \rightarrow \pi / 2, \beta_{c} \rightarrow \pi / 2$. Although the singularities in the corner diffracted fields emanating from the corners of a given polygonal plate can be shown to cancel one another, the resulting total backscattered field depends on the limiting values of $F$ in (2) for the different edges of the plate. Since the latter are nonunique, so is the value of the backscattered field.

\section{Dissertation Abstract}

\section{Probe-Corrected Spherical Near-Field Antenna Measurements}

FLEMMING HOLM LARSEN, MEMBER, IEEE

Ph.D., LD 36, Electromagnetics Institute, Technical University of Denmark, December 1980.

Manuscript received March 23, 1984.

The author is with Electromagnetics Institute, Technical University of Denmark, DK-2800 Lyngby, Denmark.
Near-field measurement on a spherical surface plus subsequent transformation to the far field is a powerful method of antenna measurements because the radiation characteristics can be determined in all directions. The thesis presents a detailed account of the theory for the near-field transformation including correction for the receiving characteristics of the probe. The coupling between the test antenna and the probe is described in terms of a scattering matrix for each antenna plus coefficients for rotation and translation of spherical modes. No arbitrary factors are involved in the formulation which is based on power-normalized modes yielding formulas for determination of directivity and gain. The definitions of the rotation and translation coefficients are critically reviewed in appendices.

The second half of the thesis treats the transformation algorithm. Various orthogonality integrals and numerical techniques for their evaluation are reviewed. The Wacker algorithm where the input data are Fourier transformed in both $\phi$ and $\theta$ is chosen for implementation. A new recurrence formula and a convolution summation method are developed resulting in a vast improvement in efficiency. The resulting computer program, SNIFTC, is used on an exact mathematical test case including probe correction. The test case demonstrates the accuracy of the near-field transformation as well as the influence of sampling.

The work led to the first spherical near-field measurements with probe correction [1] in 1977 and has since then been the basis for development of accurate antenna testing methods at the Technical University of Denmark.

References are given to papers and reports where the practical aspects of spherical near-field measurements and probe correction are demonstrated.

\section{REFERENCES}

[1] F. Holm Larsen, "Probe correction of spherical near-field measurements," Electron. Lett., vol. 13, no. 14, pp. 393-395, July 1977. 